Espacio y Desarrollo $\mathrm{N}^{\circ} 35,2020$, pp. 149-171 (e-ISSN 2311-5734)

https://doi.org/10.18800/espacioydesarrollo.202001.006

\title{
USO DESIGUAL DEL ESPACIO RECREATIVO PÚBLICO EN EL CONTEXTO de la COVID-19 en Lima Metropolitana ${ }^{1}$
}

\author{
Gloria Estefany Chambi Chamorro \\ https://orcid.org/0000-0002-2046-0624 \\ Universidad Nacional Mayor de San Marcos \\ gloria.chambi@unmsm.edu.pe \\ Josselin Huachaca Pozo \\ https://orcid.org/0000-0001-7048-1004 \\ Universidad Nacional Mayor de San Marcos \\ josselin.huachaca@unmsm.edu.pe \\ Eva Alejandra Poma Monrroy \\ https://orcid.org/0000-0002-1167-1403 \\ Universidad Nacional Mayor de San Marcos \\ eva.poma@unmsm.edu.pe
}

Fecha de recepción: 9/11/2020

Fecha de aceptación: 18/11/2020

\section{RESUMEN}

El aislamiento obligatorio producido por la pandemia de la COVID-19 ha evidenciado la necesidad de poder recrearse o generar un vínculo social, no solamente para gozar de un bienestar físico, sino mental es realmente tal: una necesidad. Ante la «nueva normalidad», el gobierno peruano ejecutó medidas para la reincorporación de las actividades recreativas individuales, así surge la necesidad de analizar las desigualdades socioespaciales para acceder a un espacio recreativo público de calidad próximo al lugar de residencia, el uso y frecuencia en función del antes, durante y después de la cuarentena, y las políticas públicas que se vienen ejecutando para el adecuado uso de los espacios recreativos públicos en Lima Metropolitana, las cuales fueron evaluadas a través de una encuesta virtual. Se concluye que es necesario proporcionar espacios de calidad que aseguren el uso seguro y equitativo, para satisfacer las necesidades sociales

\footnotetext{
1 Este trabajo fue realizado en el marco del curso de Planificación Urbana con asesoría de la magíster Tania Herrera Romero, para quien estamos totalmente agradecidas.
} 
e individuales y evitar el desplazamiento en búsqueda de espacios idóneos, a fin de reducir el incremento de contagios.

Palabras clave: COVID-19, espacios recreativos públicos, desigualdades, políticas públicas.

\section{Unequal use of public recreational space in the context of COVID-19 in Metro- politan Lima}

\section{Abstract}

The compulsory isolation produced by the Covid-19 pandemic has evidenced the need to be able to recreate or generate a social link, not only to enjoy physical well-being, but also mental well-being is really such: a necessity. Faced with the "new normality», the Peruvian government implemented measures for the reincorporation of individual recreational activities, so the need arises to analyze the socio-spatial inequalities to access a quality public recreational space near the place of residence, the use and frequency depending on the before, during and after quarantine, and the public policies that are being implemented for the proper use of public recreational spaces in Metropolitan Lima, which were evaluated through a virtual survey. It is concluded that it is necessary to provide quality spaces that ensure safe and equitable use that meet social and individual needs and avoid displacement in search of suitable spaces in other places, thus avoiding the increase of contagions.

Keywords: COVID-19, public recreational spaces, inequalities, public policies.

\section{INTRODUCCIÓN}

Las enfermedades epidemiológicas resultan imprevisibles y causan un grado de incertidumbre por la magnitud de propagación en la población; por ejemplo, actualmente, con la movilización internacional —vuelos aéreos — se incrementó la expansión del virus y es que su relación con la globalización no resulta ajena, así lo explica la geógrafa Évelyne Mesclier (2020) donde analiza que el coronavirus se desplaza siguiendo los mismos esquemas de los flujos que articulan nuestras redes económicas y las interacciones sociales mediante las interconexiones. Esto puede evidenciarse al momento de la propagación del virus desde China el cual fue expandiéndose hacia las principales ciudades de los continentes de Asia, Europa y Norteamérica.

En América Latina, aunque el virus llegó después, también impactó a los principales países con mayores conexiones como Brasil y México. En Perú también surgió la misma dinámica, siendo la ciudad de Lima la primera en presentar casos de contagios, exactamente en distritos con mayor nivel socioeconómico por el uso frecuente de movilización internacional.

Es así como el 11 de marzo la Organización Mundial de la Salud (OMS) (2020) declaró como pandemia a la COVID-19, y se realizaron recomendaciones a todos los 
países sobre la necesidad de activar protocolos de emergencia sanitaria para frenar la propagación del virus. En el Perú, ese mismo día, el Ministerio de Salud (Minsa) emitió la Declaratoria de Emergencia Sanitaria ${ }^{2}$ por noventa días con una serie de medidas en respuesta a las necesidades médicas que se darían en los posteriores meses.

Ante el aumento significativo de contagios y a fin de coadyuvar con la prevención, el Gobierno Nacional dispuso el 15 de marzo el «Estado de Emergencia Nacional y aislamiento social obligatorio» ${ }^{3}$ que, entre otras cosas, se tradujo en la restricción del derecho al libre tránsito, y la no utilización de los espacios recreativos públicos.

Se ha considerado, para efectos de la presente investigación, a los espacios recreativos públicos como: aquel lugar de acceso público abierto (León, 1998, p. 31) donde todo ciudadano ejerce su derecho de libertad al acceso de equipamientos, infraestructuras y servicios, sin restricción alguna para actividades recreativas o deportivas que puede ser de propiedad pública o privada pero de acceso libre en la población de una ciudad, comuna o vecindario; activo por el tipo de actividades que se desarrollan en él, tales como actividades de esparcimiento, disciplinas lúdicas, artísticas y deportivas; pasivo (Ocampo, 2008, p. 113) aptas para la realización de actividades contemplativas con el fin del disfrute escénico y salud física y mental. Además, es un espacio que genera un vínculo de socialización, el cual permite la interacción de una o más personas de diferentes ámbitos y estratos sociales a fin de ayudar a incentivar la tolerancia y respeto, debido al uso de áreas comunes. Cabe mencionar que por fines prácticos la investigación solo se enfocará en analizar los parques y lozas deportivas de Lima Metropolitana, ya que según encuestas de Ipsos 2020 (RPP, 2020) son los principales espacios de recreación y satisfacción, siendo los más emblemáticos y de mayor frecuencia.

La crisis sanitaria se expresó en el colapso de centros médicos y la falta de personal de salud, y motivó a que el Gobierno extendiera la cuarentena obligatoria por más de cien días. Esto significó la suspensión de diferentes actividades que implican contacto o interacción con más personas, lo que afectó las diversas actividades económicas y sociales. Ante el vertiginoso aumento de problemas de salud física y mental en la población, el Minsa (2020) publicó la «Guía Técnica para el Cuidado de la Salud Mental de la Población Afectada, Familias y Comunidad». En este documento se reconocen algunos síntomas que enfrentan las personas a causa del aislamiento social, como las emociones negativas, ansiedad, temor, tristeza y preocupación.

Por otra parte, Huacaya (2020) médico psiquiatra realizó un análisis de la salud mental en el contexto de pandemia identificando que, ante la falta de un tratamiento definitivo para controlar el virus, el incremento de defunción y la desinformación en los medios de comunicación ha generado un comportamiento errático entre las personas

\footnotetext{
Decreto Supremo 008-2020-SA.<https://bit.ly/3pEePZ2>

3 Decreto Supremo 044-2020-PCM <https://bit.ly/3dy5WO2>
} 
por la especulación sobre el modo y la velocidad de transmisión de la enfermedad. Esta situación sumado a la cuarentena, viene generando problemas psicológicos y mentales, principalmente por el distanciamiento entre personas o por la restricción en la comunicación interpersonal; además se ha reflejado altos niveles de ansiedad en la población; por ejemplo, la susceptibilidad en interpretar sensaciones corporales inofensivas como evidencia de que se encuentran infectados, lo que intensifica la falta de capacidad en la toma decisiones racionales y en su comportamiento. También se pudo identificar a los grupos de alto riesgo (Paricio \& Pando, 2020, p. 33), siendo las mujeres, estudiantes universitarios y los adultos mayores más vulnerables ante los problemas de salud mental ocasionada por la pandemia.

Nuestra investigación surgió en junio de 2020, tras el permiso emitido por el Minsa para la reincorporación de actividades físicas y recreacionales en varios distritos de Lima Metropolitana ${ }^{4}$, con excepción de diecinueve distritos donde se presentó un incremento en el índice de contagios. Ante lo mencionado, consideramos esta medida como un acto de exclusión al privilegiar solo a algunos sectores más acomodados de la ciudad al uso de los espacios recreativos públicos y restringir los derechos de recreación a los sectores más vulnerables, ósea a los residentes de menores ingresos que habitan en los distritos periféricos.

En este contexto, nos propusimos como objetivo analizar los usos de los espacios recreativos públicos en el contexto de la COVID-19, con énfasis en la adaptación de las actividades de la población frente al imperativo de distanciamiento social y las restricciones del uso impuestas por las autoridades. A manera de hipótesis, consideramos que la prohibición de uso de los espacios recreativos públicos en algunos distritos fomenta que las personas se desplacen mayores distancias en busca de áreas recreativas cuyo uso no esté restringido, lo cual se traduce en un incremento de la probabilidad de contagio.

\section{Metodología}

El estudio combina el análisis de información cualitativa y cuantitativa. La primera en mención estuvo basada en fuentes primarias y secundarias relacionadas al estudio de espacios públicos. Por lo que respecta a la dimensión cuantitativa, el análisis se centró en datos obtenidos de la encuesta virtual difundida desde el veintiocho de agosto hasta el siete de septiembre de 2020, a través de diferentes grupos sociales, páginas de universidades y otros, la cual se realizó exclusivamente en Lima Metropolitana. Dicha encuesta incluyó preguntas de opción múltiple, la cual contenía la opción "otra» como una alternativa de respuesta, a fin de no limitar las respuestas de la población encuestada, y a la vez se incluyó una pregunta abierta para conocer la opinión pública.

\footnotetext{
4 Resolución Ministerial 350-2020-Minsa, p.3 <https://bit.ly/3qIM0vE>
} 
A partir de ella, se obtuvo una muestra de 268 personas encuestas, las cuales fueron clasificadas según la zonificación propuesta por el Instituto Nacional de Estadísticas e Informática (INEI) en 2014, la cual categoriza el área de Lima Metropolitana en Lima Norte ${ }^{5}$, Lima Centro ${ }^{6}$, Lima Sur ${ }^{7}$, Lima Este $^{8}$ y Callao 9 . Asimismo, la zona con el mayor número de encuestados es Lima Este y Lima Norte, mientras que Callao obtuvo pocas respuestas; sin embargo, se optó por incluirlo dentro del análisis, por su importancia dentro de la conurbación de Lima Metropolitana.

Figura 1. Ubicación del área de estudio

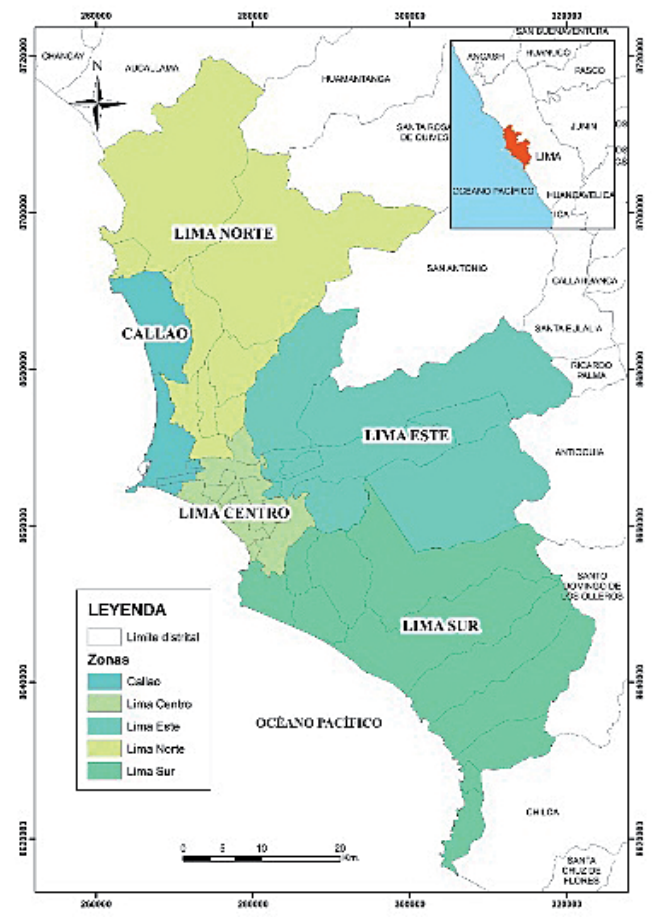

Fuente: Elaboración propia (2020).

5 Distritos que conforman Lima Norte: Ancón, Carabayllo, Comas, Independencia, Los Olivos, Puente Piedra, San Martín de Porres y Santa Rosa.

6 Distritos que conforman Lima Centro: Barranco, Breña, Jesús María, La Victoria, Lima, Lince, Magdalena del Mar, Miraflores, Pueblo Libre, Rímac, San Borja, San Borja, San Isidro, San Miguel, Santiago de Surco y Surquillo.

7 Distritos que conforman Lima Sur: Chorrillos, Lurín, Pachacámac, Pucusana, Punta Hermosa, Punta Negra, San Bartolo, San Juan de Miraflores, Santa María del Mar, Villa El Salvador y Villa María del Triunfo.

8 Distritos que conforman Lima Este: Ate, Chaclacayo, Cieneguilla, El Agustino, La Molina, Lurigancho, San Juan de Lurigancho, San Luis y Santa Anita.

9 Distritos que conforman Callao: Bellavista, Callao, Carmen de la Legua Reynoso, La Perla, La Punta, Mi Perú y Ventanilla. 
Este artículo se estructura en tres partes. En la primera, aborda la percepción de la población con respecto a las desigualdades en la distribución de los equipamientos recreativos públicos en Lima Metropolitana, en función a la cantidad y calidad de ellos. Seguidamente, se aborda los usos del espacio recreativo antes, durante y después de la cuarentena, así como la relación espacio-vivienda, el cual será contrastado con la necesidad de acudir a los espacios recreativos, las actividades que se realizaban dentro de ellas y el cambio inminente que se dio ante la coyuntura actual. Por último, se analizan las políticas y medidas ejecutadas en los espacios recreativos públicos, así como la opinión de los usuarios ante las medidas propuestas por el gobierno. A partir de este punto, se utilizará el acrónimo ERP para referirse a los espacios recreativos públicos.

\section{Desigualdades en Lima Metropolitana frente al equipamiento de LOS ESPACIOS RECREATIVOS PÚBLICOS}

Las dinámicas sociales en los ERP permiten una diversidad de procesos que pueden o no coexistir armónicamente, porque deben atender necesidades de vecinos y visitantes, así como necesidades individuales y colectivas.

Así, para entender el comportamiento de los usuarios de estos espacios, se considera como base, el análisis de las discrepancias denominadas en esta investigación como desigualdades. Esta puede considerarse socio-espacial debido a la ubicación diferencial de las personas en el territorio en relación con su capacidad económica y/o condición social; sin embargo, recientemente se han incluido otros indicadores como el medio ambiente, el bienestar social o la accesibilidad, que amplían y complejizan el análisis de las desigualdades (Garcia-Hernández, 2017). Por ello, el análisis de desigualdades está orientada en función a cómo percibe la población encuestada la cantidad y calidad de los ERP en relación con su ubicación zonal en Lima Metropolitana, porque la distribución desigual de los espacios públicos genera un problema de inequidad social ya que afecta principalmente a los ciudadanos más pobres que residen en zonas donde los espacios públicos son inexistentes o insuficientes (García \& Lara, 2016).

Por otro lado, Borja, citado por Vega (2017), afirma que la ciudad es el espacio público, porque permite una afirmación plena de la ciudadanía, para todos y por igual; aunque esta conceptualización se puede alejar de la realidad. En el ámbito de las ciudades latinoamericanas estos atributos asignados al espacio público funcionan de manera bastante diferente, debido a que nuestras ciudades no solo son la expresión territorial de las grandes desigualdades estructurales de la economía y la sociedad, sino que son generadoras de otras desigualdades de tipo territorial (Reygadas \& Ziccardi, 2010).

Las desigualdades presentes en los ERP — denominados también como espacio abierto- muchas veces guardan una relación causativa con la idea de disparidad entre zonas centrales y periféricas. Ziccardi (2013) refiere que existen espacios públicos 
localizados en diferentes zonas socioeconómicas con características muy desiguales entre sí, respecto al tamańo, calidad, forma de uso y, muchas veces, en lo referente a su deterioro, dado que, en lugar de promoverse, afecta los procesos de construcción de ciudadanía y fortalecimiento de la identidad comunitaria. Es así que se analizó los ingresos per cápita del hogar por distrito según los planos estratificados de Lima Metropolitana a nivel de manzana realizados por INEI (2020), con el objetivo de visibilizar la relación entre su ubicación zonal y el nivel de ingresos monetarios. Los distritos de Lima Centro presentan una mayor cantidad de hogares con ingresos medio alto y alto, en el cual destaca Jesús María, Magdalena del Mar, Miraflores y San Isidro con un 100\% de hogares con ingresos altos; mientras que los distritos de Lima Sur, Lima Norte y Lima Este presentan hogares que tienen ingresos bajos - menores al sueldo mínimo- entre ellos destaca Pucusana con un 68\%; Punta Hermosa, el 60\%; Santa Rosa, el 45\%; Lurigancho, el 42\%; San Juan de Lurigancho, el 38\% y Ate con el 37\%.

En Lima Metropolitana las personas que perciben una mayor satisfacción de los espacios públicos se encuentran en la centralidad, producto de su ubicación encuentran más y mejores equipamientos urbanos en relación con el resto de las zonas, el cual genera un desarrollo territorial desigual. Según Gutiérrez (2012) menciona que en la centralidad se encuentran espacios urbanísticamente bien equipados, con una marcada tendencia a la consolidación y densificación. Esta información lo corrobora la encuesta Lima Cómo Vamos (2019), en el que señala que la zona central de la ciudad comprendidos por los distritos de Barranco, Breña, Jesús María, Lima, La Victoria, Lince, Magdalena del Mar, Miraflores, Pueblo Libre, Rímac, San Borja, San Isidro, San Luis, San Miguel, Santiago de Surco y Surquillo, concentra las opiniones más favorables referentes a los espacios público.

Las desigualdades relacionadas a la calidad de los espacios públicos persisten porque son consideradas como problemas de segundo orden ${ }^{10}$, en lugar de ser entendidos como una necesidad urgente de inclusión social como experiencia urbana (Vega Centeno, 2017). De manera que, de esta desatención se derivan nuevos problemas como la percepción de peligro o inseguridad dentro de los ERP. Esta percepción se vincula con la presencia de pintas de grafiti, basura, equipos en mal estado, falta de iluminación, así como con personas involucradas en actividades consideradas riesgosas (García \& Lara, 2016).

En concordancia con lo anterior, existe una relación causa- efecto entre la calidad —expresado en el nivel de mantenimiento — del equipamiento, infraestructura ${ }^{11}$

\footnotetext{
${ }^{10}$ Vega Centeno afirma que es un problema de la ciudad apenas percibida por la población, sumado a que los estudios urbanos han concentrado su atención en los problemas y conflictos urbanos generados por la tenencia del suelo.

${ }^{11}$ Aquellas relacionadas a los espacios recreativos como el alumbrado público, veredas, ciclovías y rampas.
} 
y/o mobiliario ${ }^{12}$ del ERP con la percepción del nivel de seguridad dentro del mismo. En las encuestas realizadas, la población de Lima Centro y el Callao manifiesta tener una mejor calidad del ERP y que se relaciona con el grado de seguridad que perciben; por el contrario, en Lima Sur, Lima Norte y Lima Este la calidad de sus ERP es deficiente lo que disminuye su percepción de seguridad (véase en la Tabla 1). Por eso, es responsabilidad de las autoridades locales tener una mejor gestión pública para reducir las brechas de la desigualdad territorial en función a los equipamientos, infraestructura y mobiliario, de modo que se brinde el mantenimiento adecuado para asegurar su función a través del tiempo.

Tabla 1. Relación entre la calidad del equipamiento, infraestructura y/o mobiliario con el nivel seguridad dentro del espacio recreativo público (porcentaje)

Estado de mantenimiento del equipamiento (\%)

\begin{tabular}{lccccc}
\hline & Lima norte & Lima Centro & Lima Este & Lima Sur & Callao \\
\hline Bueno & 21 & 39 & 19 & 11 & 58 \\
Medio & 48 & 51 & 63 & 47 & 33 \\
Malo & 28 & 5 & 18 & 36 & 9 \\
No observado & 3 & 5 & 0 & 6 & 0 \\
\hline
\end{tabular}

Estado de mantenimiento de la infraestructura y/ mobiliario (\%)

\begin{tabular}{lccccc}
\hline & Lima Norte & Lima Centro & Lima Este & Lima Sur & Callao \\
\hline Bueno & 10 & 42 & 16 & 8 & 42 \\
Medio & 44 & 42 & 46 & 42 & 50 \\
Malo & 28 & 9 & 35 & 35 & 8 \\
No observado & 18 & 7 & 3 & 15 & 0 \\
\hline
\end{tabular}

Nivel de seguridad (\%)

\begin{tabular}{lccccc}
\hline & Lima Norte & Lima Centro & Lima Este & Lima Sur & Callao \\
\hline Alto & 7 & 39 & 8 & 2 & 20 \\
Medio & 40 & 41 & 39 & 30 & 40 \\
Bajo & 53 & 20 & 53 & 68 & 40 \\
\hline
\end{tabular}

Fuente: Elaboración propia con datos de la encuesta realizada en septiembre 2020. Se consideró la opción «no observado» porque se presentan zonas sin equipamiento, infraestructura y/o mobiliario.

Para abordar esta problemática de desigualdad con relación a los ERP, se resalta la situación del parque «El Hueco», ubicado en el Asentamiento Humano Javier Heraud del distrito de San Juan de Miraflores (Lima Sur). Anteriormente, este lugar

${ }^{12}$ Referido a bancas, tachos de basura, etc. 
sirvió como relleno sanitario, convertido luego en una zona de recreación pública (parque), mediante políticas municipales que mejoran estéticamente el espacio público. A mediados de 2005, según imágenes espaciales de Google Earth Pro, presentaba un acondicionamiento dotado de equipamientos como losas deportivas y área de juegos, y una gran extensión de cobertura vegetal. Sin embargo, con el paso del tiempo, la calidad de dicho espacio recreativo público fue decayendo, lo cual ha resultado en que, actualmente, se evidencie una calidad deplorable, reflejada en la inexistencia de aquella extensa área verde y el retiro del área de juego por encontrarse deteriorado, sin prever su posterior reemplazo; por este motivo, la implementación y promoción de ERP no simplemente debe basarse en la construcción para su posterior inauguración, sino que debe resultar viable a través del tiempo mediante el mantenimiento. Ante ello, ha surgido una percepción de un vínculo de pertenencia de la población, el cual ha permitido que la organización vecinal recupere el ERP. Esto se ha traducido en una actitud de toma de responsabilidad en lo concerniente al mantenimiento de pequeños sectores contiguos a su hogar.

No obstante, bajo otra perspectiva el vínculo de pertenencia, la percepción puede ser negativa, debido a las prácticas de enrejado del ERP, las cuales han sido implementadas en mayor proporción en las zonas residenciales, lo que genera un uso exclusivo de los vecinos, pero que imposibilita el uso para personas de paso, que no son vecinos de la zona, lo cual limita la accesibilidad. Estas prácticas de enrejado carecen de una correcta regulación y fiscalización ante la ausencia de medidas legales relacionadas a los espacios públicos.

Por otra parte, la provisión de espacios públicos es de poca utilidad si no se acompaña con acciones deliberadas para producir espacios de calidad y adecuados a las necesidades de una población diversa y cambiante (García \& Lara, 2016). En este sentido, al analizar la cantidad de ERP en Lima Metropolitana en función a la percepción de la población encuestada, se encontró una distribución casi homogénea de los equipamientos, es decir del total de equipamiento recreativos percibidos, el 20,4\% se presenta en el Callao, en Lima Este el 19,8\%, en Lima Sur y Lima Norte (16,9\% y 16,7\% respectivamente) tienen escasos equipamientos el cual no permite un correcta recreación de los niños y un desarrollo diversificado de actividades deportivas; mientras que en Lima Centro presenta un nivel más alto $(26,2 \%)$ de los ERP ya que presenta una gran cantidad de áreas de juegos y mini gimnasios. Asimismo, se evidencia que, en todas las zonas, los parques y losas deportivas son los equipamientos destacados; aunque esta última se presenta más en los barrios populares (ver Figura 2). 
Figura 2. Distribución de tipos de equipamientos en Lima Metropolitana

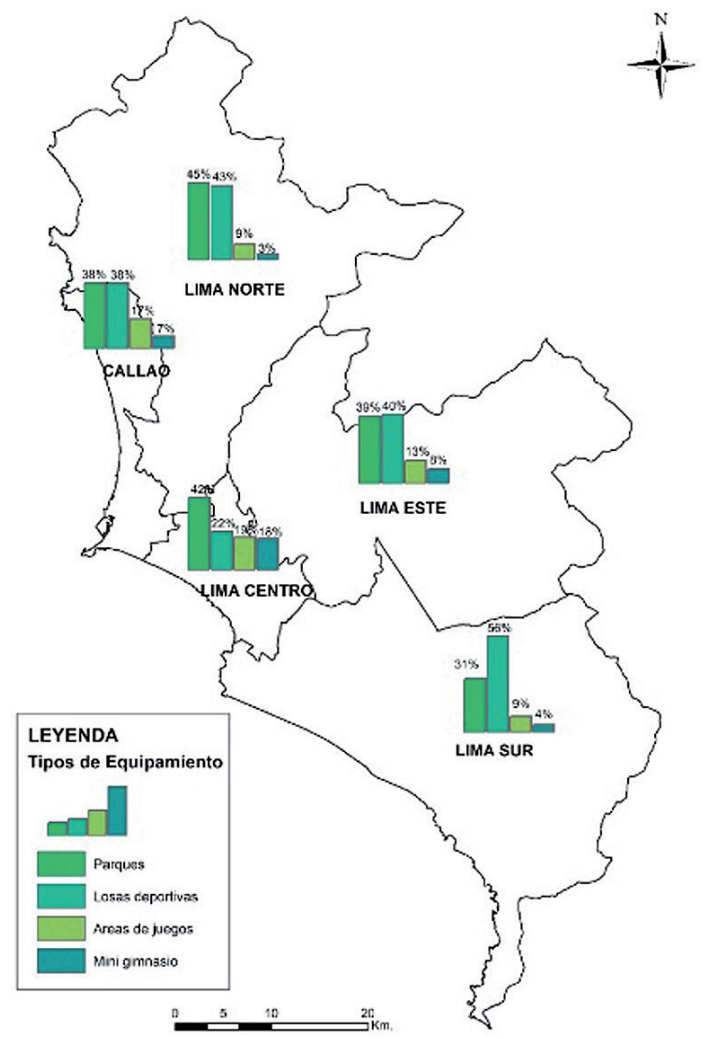

Fuente: Elaboración propia con datos de la encuesta realizada en septiembre 2020.

Por las diferencias presentes en los ERP de Lima Metropolitana, se preguntó a la población por sus deseos y aspiraciones en relación con los equipamientos recreativos en los ERP de su barrio. En ese sentido, la mayoría de las personas coinciden en que les gustaría contar con más minigimnasios y áreas de juegos, con excepción de Lima Sur donde un 30\% le gustaría una mayor cantidad de parques.

Ante esta situación, una de las medidas para contrarrestar estas diferencias de espacios recreativos en las zonas periféricas de Lima Metropolitana fue la implementación de diez clubes zonales administrados por el Servicio de Parques de Lima (Serpar), pero orientado a una población con la capacidad de pagar por este servicio, la cual excluía a los sectores más pobres e intensificando la idea de desigualdad.

Es así que ante el contexto de pandemia, las desigualdades en los ERP resaltan por la limitaciones que algunas zonas tienen para acceder a espacios de calidad próximos a su hogar, el cual no permite satisfacer los diferentes usos y propiciando el desplazamiento de los usuarios en búsqueda de espacios que suplan sus necesidades. 


\section{USO Y FRECUENCIA DEL ESPACIO RECREATIVO PÚBLICO}

Para Boils y Galeana (2017) el concepto de habilitación implica la interacción y relación social en el espacio público. Este es transformado física y socialmente por el sujeto, individual o colectivo, mediante las prácticas cotidianas; de ese modo, se busca la satisfacción de sus necesidades recreativas, lo cual deviene en un proceso de apropiación ${ }^{13} \mathrm{y}$, finalmente, en el uso de dicho espacio. La apropiación dependerá de las necesidades de satisfacción de las personas, el entorno a los grupos sociales y, a fin de buscar dichas satisfacciones, requerirá el desplazamiento a estos espacios.

El uso y apropiación del espacio urbano está mediado por la frecuencia y disfrute que se hace con fines recreativos, deportivos, de ocio, de desplazamiento o actividades comunitarias en las que intervienen razones intrapersonales, socioculturales y físicoambientales (Cardona, 2008). Es en este sentido que, según las investigaciones de Castro y coautores (2008), los elementos relacionados con la apropiación de los espacios urbanos guardan relación con aspectos socioculturales, pero también demográficos, dado que está asociados a la edad y el género. Cardona (2008) menciona que existen preferencias según el grupo de edad para acceder a los espacios recreativos. Así, para los grupos entre 25 y 29 años y para el grupo entre 40 y 44 años, la principal razón es la recreación: caminar o hacer deporte. En contraste, para la población comprendida en el grupo de edad que oscila entre los 30 y 39 años, la principal razón es incorporarse a un entorno social. Para los adultos entre 45 y 50 ańos, finalmente, es el gusto, la afición o la comodidad resultante de estar un espacio recreativo.

La encuesta realizada y difundida en Lima Metropolitana permitió tener una visión más amplia acerca del uso y frecuencia de los ERP. Es así que los resultados de dicha encuesta refleja una mayor participación por parte de la población joven que se encuentra dentro del rango de edad 20 y 29 años $(73,3 \%)$ y del género femenino (58\%) y que el principal uso de los ERP es realizar paseos y actividades de recreación y disfrute, sostenido bajo la definición de Castro et al. (2008) que menciona la preferencia por acudir a los espacios públicos en función al género; como ejemplo, toma la preferencia de los hombres por acudir a los espacios deportivos ${ }^{14}$, mientras que las mujeres optan por el parque principal. También se refiere a la preferencia en función de la edad: la población más joven tiende a acudir a escenarios deportivos y recreativos, a diferencia de la población adulta, que optará por el parque principal y las plazas.

El tamaño de la vivienda es un factor decisivo en el uso que los habitantes hacen del espacio público, Boils (2017) plantea que este es un factor determinante puesto que lleva a los habitantes a hacer el uso de espacio abierto en función a las actividades

\footnotetext{
${ }^{13}$ La apropiación refiere al sentido de pertenencia que experimentan los individuos o colectividades (Lindón, 2006, p. 384).

${ }^{14}$ Entre los que se encuentran las losas deportivas.
} 
que realiza día a día; asimismo toma en cuenta la importancia del diseño de los espacios públicos y la relación que debe tener con el tamaño de la vivienda en diversas escalas (entorno en el que la vivienda está comprendida) ya que la interacción de ambos, con el tiempo se vuelve cambiante ${ }^{15}$ y conflictivo ${ }^{16}$.

De acuerdo con el censo nacional de 2017: XII de población, VII de vivienda y III de Comunidades indígenas, el $71 \%$ de hogares en lima metropolitana vive en casas, mientras el $24 \%$ vive en edificios; estos datos se pueden corroborar en la encuesta realizada, donde la población que vive en casas y edificios corresponde al 78,3\% y $12,6 \%$ respectivamente (visualizar Tabla 2). Se preguntó a la población si el tamaño de la vivienda influía en la necesidad de acudir a los espacios recreativos y un 64,6\% respondió afirmativamente; sin embargo, de este grupo el 75,7\% vive en una casa, por lo que la necesidad de recrearse en un ERP debería ser menor a comparación de una persona que vive en un departamento. Estos datos se pueden explicar ya que el mayor número de encuestados corresponde a la población joven que se encuentra en un rango de edad 20 a 29 años, donde tienden a salir y acceder a los ERP a fin de satisfacer sus necesidades de recreación y disfrute.

Tabla 2. Relación al tamaño de la vivienda con el acceso a los espacios públicos según la población encuestada

\begin{tabular}{lcccccccc}
\hline & \multicolumn{2}{c}{ Casas } & \multicolumn{2}{c}{$\begin{array}{c}\text { Departamento } \\
\text { en edificio }\end{array}$} & \multicolumn{2}{c}{$\begin{array}{c}\text { Cuarto } \\
\text { alquilado }\end{array}$} & \multicolumn{2}{c}{ Otros } \\
\hline Zonas & $\mathrm{Si}$ & No & $\mathrm{Si}$ & No & $\mathrm{Si}$ & No & $\mathrm{Si}$ & No \\
\hline Norte & 37 & 23 & 3 & 0 & 3 & 1 & 1 & 0 \\
Centro & 12 & 7 & 13 & 7 & 2 & 0 & 1 & 1 \\
Sur & 34 & 22 & 2 & 0 & 4 & 0 & 0 & 0 \\
Callao & 4 & 4 & 0 & 1 & 0 & 0 & 2 & 0 \\
Este & 45 & 21 & 4 & 4 & 7 & 3 & 0 & 0 \\
\hline
\end{tabular}

Fuente: Elaboración propia con datos de la encuesta realizada en septiembre 2020.

Según Cardona (2008), la población frecuenta los espacios recreativos para desarrollar actividades recreativas o deportivas, para interactuar con otros, por afición y por comodidad. Por otro lado, Calero y coautores (2014) menciona que los espacios públicos ejercen una triple función: urbanística, ambiental y social, siendo elementos estructurantes del tejido urbano, ordenadores de la trama, orientan el crecimiento y se convierten en nodos que facilitan la conectividad. Dicho esto, se analiza el uso y frecuencia referente a los espacios recreativos en función al antes, durante y después de la cuarentena decretada por el gobierno del Perú (15 de marzo de 2020). Los resultados

\footnotetext{
15 Referido al uso de los espacios públicos a través de los años.

${ }^{16}$ Referido a los espacios abiertos privados que ingresan una mínima parte de la población.
} 
muestran que antes de la cuarentena el 61,4\% de los encuestados acudía a los ERP, de una a tres veces por semana. Las actividades que realizaban dentro del espacio eran paseos, deporte y encontrarse con amigos o familiares $(27 \%, 25 \%$ y $24 \%$ respectivamente). De esta manera se enfatiza la importancia del espacio público en la vida de las personas y en las actividades que realizaban antes que la nueva normalidad interrumpiera en la vida de todos.

Otro de los indicadores fue el medio de transporte para acceder a los ERP, así como el tiempo de desplazamiento para acudir a ellos. Se obtuvo que la mayoría accedía caminando o en transporte público y que el tiempo promedio que se toman en llegar a estos es de cero a cinco minutos, seguido de seis a diez minutos. Esto indica que gran parte de la población cuenta con un espacio público cercano a su hogar; sin embargo, más de la mitad de la población encuestada, prefieren recorrer distancias más largas en busca de un espacio recreativo de mejor calidad con la finalidad de satisfacer sus necesidades (ver Tabla 3).

Tabla 3. Uso, frecuencia, medio de transporte y necesidad de ir a otro ERP en función al antes, durante y después de la cuarentena

\begin{tabular}{|c|c|c|c|c|}
\hline & & $\begin{array}{c}\text { Antes de la } \\
\text { Durante }\end{array}$ & $\begin{array}{l}\text { Durante la } \\
\text { cuarentena }\end{array}$ & $\begin{array}{c}\text { Después de } \\
\text { la cuarentena }\end{array}$ \\
\hline \multirow{4}{*}{$\begin{array}{l}\text { Número de días } \\
\text { que sale a un } \\
\text { espacio público }\end{array}$} & Todos los días & 14 & 1 & 6 \\
\hline & 4-6 Días & 50 & 3 & 19 \\
\hline & 1-3 Días & 165 & 20 & 79 \\
\hline & Ningún día & 39 & 207 & 164 \\
\hline \multirow{6}{*}{$\begin{array}{l}\text { Actividades que } \\
\text { realizan dentro del } \\
\text { espacio público }\end{array}$} & Paseo & 149 & 21 & 45 \\
\hline & Deporte & 142 & 7 & 26 \\
\hline & Manejar bicicleta & 86 & 15 & 23 \\
\hline & Encuentro con vecinos, amigos, otros & 134 & 7 & 27 \\
\hline & No realizo ninguna actividad & 33 & 116 & 73 \\
\hline & Otros & 13 & 5 & 13 \\
\hline \multirow{7}{*}{$\begin{array}{c}\text { Tipo de } \\
\text { movilización para } \\
\text { desplazarse a un } \\
\text { espacio público }\end{array}$} & Caminando & 91 & 25 & 38 \\
\hline & Bicicleta & 36 & 7 & 15 \\
\hline & Transporte Público & 91 & 16 & 18 \\
\hline & Auto privado & 27 & 3 & 7 \\
\hline & Taxi & 12 & 1 & 4 \\
\hline & Otros & 27 & 3 & 5 \\
\hline & Ninguno & 31 & 83 & 68 \\
\hline \multirow{2}{*}{$\begin{array}{c}\text { Necesidad de } \\
\text { desplazarse a otro } \\
\text { espacio recreativo }\end{array}$} & $\mathrm{Si}$ & 184 & 25 & 63 \\
\hline & No & 84 & 243 & 205 \\
\hline
\end{tabular}

Fuente: Elaboración propia con datos de la encuesta realizada en septiembre 2020. 
Durante el período de confinamiento obligatorio que el gobierno central impuso, el 91\% no acudió a los ERP, lo que indica un respeto a las medidas preventivas que el gobierno estipulaba. Por otro lado, la población sobrante que acudía a los ERP, eran principalmente jóvenes de 20 a 29 años y la actividad que realizaban dentro del ERP era dar paseos. Un dato que resalta es que utilizan transporte público para poder llegar a un espacio público, reflejando así la necesidad de poder desplazarse largas distancias a pesar de las restricciones estipuladas por el estado.

Al término del aislamiento social obligatorio para Lima Metropolitana (1 de julio de 2020), hubo un decrecimiento del 43,6\% con respecto al número de personas que accedían a los ERP antes de la cuarentena, además las personas que aún acceden a los ERP mantuvieron las mismas actividades que realizaban antes del confinamiento obligatorio.

Cabe resaltar que desde que inició el periodo de cuarentena, se presenció un aumento de personas que utilizaban las bicicletas como medio de transporte para acudir a sus centros de labores o con fines recreativos. Así lo confirma el estudio que hizo la Compañía Peruana de Estudios de Mercados y Opinión Pública (CPI) con referente al "uso de la bicicleta en Lima», en el que el $97 \%$ de la población encuestada ve un punto positivo el uso de la bicicleta y que el $40 \%$ de la población está dispuesta a usar una bicicleta como medio de transporte después de finalizar el estado de emergencia, esto con la finalidad de evitar contagios por COVID-19 y por la rapidez de desplazamiento. Por ello, es que la municipalidad de lima metropolitana implementó $147 \mathrm{~km}$ de ciclovías distribuidas en diferentes distritos que están conectadas unas con otras para un mejor desplazamiento por parte de los usuarios.

Ante la inminente necesidad del uso de los ERP, los lineamientos técnicos y políticos son claves para regular los usos permitidos, con el objetivo de mantener los protocolos de seguridad y regular las actividades permitidas en estos espacios.

\section{Políticas y Medidas en los espacios ReCreativos públicos (ERP)}

Ante el contexto actual, el gobierno ha implementado una serie de medidas para limitar el uso de los espacios recreativos, con el objetivo de frenar el incremento de contagios por la COVID-19.

La primera medida, se ejecutó el doce de marzo de 2020 ante la Declaratoria de Emergencia Nacional, lo que supuso el cese del ejercicio de los derechos constitucionales, como la libertad de tránsito de las personas en los espacios públicos y el aislamiento social obligatorio en un plazo de quince días, con algunas excepciones ${ }^{17}$.

\footnotetext{
${ }^{17}$ Acciones o actividades permitidas dentro de la Declaratoria de Emergencia Nacional: Los establecimientos comerciales minoristas de alimentación, bebidas, productos y bienes de primera necesidad,
} 
Esta medida de aislamiento social se prolongó con el paso de los meses, con el fin de mitigar la propagación del virus; sin embargo, también surgió incertidumbre en la población ante el incremento de contagios, las defunciones, el colapso de los centros médicos y la desinformación en los medios de comunicación. Según un estudio del Minsa y la Organización Panamericana de la Salud en una publicación para el diario El Peruano (2020); en un universo de 57250 personas mayores de edad, 7 de cada 10 peruanos estaría sufriendo problemas o síntomas relacionadas con enfermedades de salud mental, siendo los síntomas más frecuentes: dificultades para dormir $(55,7 \%)$, problemas con el apetito (42,8\%), cansancio o falta de energía (44\%), falta de concentración $(35,5 \%)$ y pensamientos o ideas suicidas $(13,1 \%)$. Esto refleja la necesidad inminente de ejecutar planes en beneficio de la salud física y mental de las personas.

Reconociendo este problema, el Minsa elaboró una «Guía Técnica para el Cuidado de la Salud Mental de la Población Afectada, Familias y Comunidad» que establece criterios técnicos y procedimientos para el cuidado y autocuidado de la salud mental de la población, en el contexto de la COVID-19.

Asimismo, Wang y coautores (2020) explica claramente los factores de estrés que vienen afectando negativamente en la salud mental de los nińos, como son la frustración de planes y el aburrimiento, la incertidumbre respecto a la duración de las medidas de confinamiento, el miedo social a la infección, las limitaciones en el disfrute del ocio y la falta de espacio personal en el domicilio. De esa manera, el dieciocho de mayo se permitió a los niños menores de catorce años utilizar los espacios públicos ${ }^{18}$, bajo la supervisión de un adulto, con un desplazamiento de 500 metros de radio desde su domicilio y cumpliendo los protocolos de seguridad sanitaria.

Del mismo modo el 3 de junio, el Minsa declaró la reactivación de actividades recreativas de uso individual ${ }^{19}$ en Lima Metropolitana. Las actividades permitidas fueron las siguientes: la caminata, marcha, trote, pilates, entrenamiento funcional, taichí, yoga, tenis, golf, ciclismo skate, patinaje y otras que no implicarán contacto directo con más personas. También se estableció un tiempo máximo de sesenta minutos, con un desplazamiento de tres kilómetros a la redonda desde su domicilio en los horarios de 5:00 a.m. a 6:00 p.m. La medida, si bien fue considerada positiva al inicio, traería controversia al ser restringido para diecinueve distritos ${ }^{20}$ de Lima Metropolitana,

\footnotetext{
establecimientos farmacéuticos, médicos, ópticas y productos ortopédicos, productos higiénicos, grifos y establecimientos de venta de combustible.

${ }_{18}$ Decreto Supremo 083-2020-PCM. <https://bit.ly/3scDCFa>

${ }^{19}$ Resolución Ministerial 350-2020-Minsa <https://bit.ly/3dDpyQX>

${ }^{20}$ Los distritos restringidos fueron: San Juan de Lurigancho, Lima Cercado, San Martín de Porres, Comas, El Agustino, Ate, San Juan de Miraflores, Santa Anita, Villa El Salvador, Villa María del Triunfo, La Victoria, Puente Piedra, Rímac, San Miguel, Chorrillos, Breña, Independencia, Los Olivos, Carabayllo y Surquillo
} 
considerados como lugares con mayor riesgo de transmisión. La medida sólo favorecía a los distritos de mayor nivel socioeconómico, lo cual generó una percepción de desigualdad, producto de la diferencia para acceder a estos espacios, debido a que la mayoría de los distritos restringidos se ubica en zonas periféricas.

Por ello, se preguntó a la población si en su distrito estaba permitido el uso de los ERP. Del total de personas encuestadas el 56\% tenían acceso a los espacios públicos, pero de esta cifra solo el 20,1\% contaban con la autorización distrital para poder acceder a estos espacios; por otra parte, el $20 \%$ indicó que no estaban autorizados en sus distritos, el $20 \%$ mencionó que solo algunos lugares estaban autorizados, y el $13 \%$ no estaban informados sobre la autorización del uso de los ERP (ver Figura 3).

Figura 3. Población encuestada que conoce las restricciones normativas relacionadas al uso de los espacios recreativos públicos en su distrito durante la cuarentena

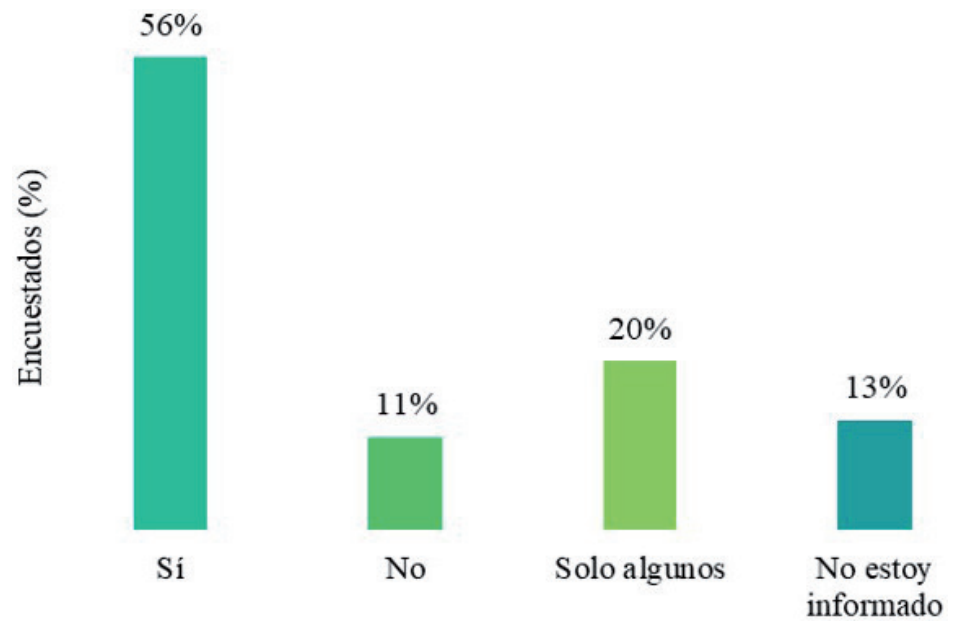

Fuente: Elaboración propia con datos de la encuesta realizada en septiembre 2020.

El primero de julio, el gobierno determinó la culminación del aislamiento social obligatorio y la paulatina reactivación económica a excepción de algunos departamentos que aún presentaban incrementos de contagios. Ante ello; en Lima Metropolitana las actividades recreativas ya no se reducían a distancias cortas, sino que estas iban incrementando su desplazamiento hacia otros distritos. La implementación de ciclovías fomentó el uso de las bicicletas e incentiva a realizar recorridos más largos para acudir a otros espacios recreativos.

Bajo las nuevas medidas era inminente la preocupación por el incremento de personas contagiadas, razón por la cual el gobierno dispuso la inmovilización los días domingo a fin de disminuir el flujo de personas, sin frenar la reactivación económica ni las actividades recreativas. 
Por tal motivo surgió la necesidad de preguntar a los encuestados si después de la cuarentena se venían implementando protocolos de seguridad sanitaria en los ERP próximos a sus hogares, lo que evidenció la escasez de estos, a excepción de Lima Centro y el Callao que cuentan con mejores EAP y donde existen mayores protocolos de seguridad por la afluencia de personas (véase Figura 4).

Figura 4. Cumplimiento de protocolos de seguridad sanitaria por zonas en espacios recreativos públicos

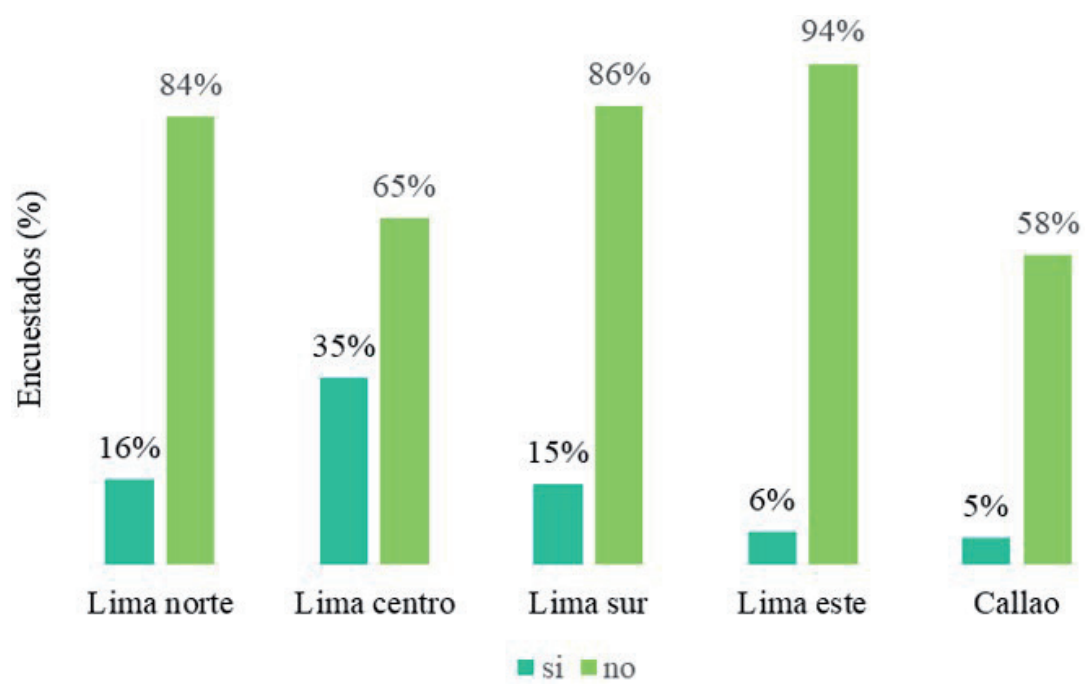

Fuente: Elaboración propia con datos de la encuesta realizada en septiembre 2020.

Con la finalidad de comprender la percepción de la población frente a la situación actual de la COVID-19, se preguntó abiertamente a la población si se debería restringir el acceso a los espacios recreativos. Los resultados dieron que un $57,5 \%$ considera que no debería prohibirse; sin embargo, consideran necesario implementar o aumentar los protocolos de seguridad. También recalcan la importancia de la recreación en los niños y la necesidad de recreación para el cuidado de la salud física y mental. Por otra parte, mencionan que es necesario la restricción a la población vulnerable (personas de la tercera edad, con problemas de enfermedades respiratorias), controlar la afluencia de personas y la importancia del cumplimiento de las medidas sanitarias al utilizar los espacios recreativos (véase la Figura 5).

Por el contrario, el 39,5\% menciona que sí es necesario prohibir el acceso al ERP a fin de evitar las aglomeraciones y así minimizar los contagios. También resaltaron la falta de protocolos de seguridad, la poca participación de las autoridades locales y la falta de conciencia social por el incumplimiento de las medidas sanitarias en la población. 
Un ejemplo de ello es el Campo de Marte, uno de los parques más importantes de Lima Centro, ubicado en el distrito de Jesús María. Ante el estado de emergencia y bajo ordenanza municipal ${ }^{21}$ se dispuso la suspensión de toda actividad social o de recreación en espacios públicos que implique una concentración de personas a fin de disminuir el número de contagios por la COVID-19, lo que implicó el cierre temporal del parque. Esta medida trajo opiniones divididas en la población; por una parte los vecinos próximos al parque, indicaron que ante el cierre del parque, la afluencia de personas no había cambiado puesto que las personas continuaron recreándose alrededor del parque, obstruyendo el paso peatonal e incrementando las aglomeraciones; por el contrario, otros se encontraban a favor de la medida ya que según los niveles de contagio por distrito, la zona 2 (alrededores del Campo de Marte) registró un incremento de casos positivos por la COVID-19. De la misma manera la autoridad local mantenía su posición en no abrir Campo de Marte con el argumento de ser un espacio de escala metropolitana, que atrae a flujo de visitantes y que no podían manejarlo por la falta de personal de seguridad e implementación de los protocolos de seguridad sanitaria (Lima cómo vamos, 2021).

Figura 5. Opinión pública ante la suspensión de actividades en espacios recreativos

\section{públicos \\ Coyuntura de Importancia de recreación BUENO PARA LA pandemia para los Minimizar SALUD FísICA Y FALTA DE niños PROTOCOLOS contagios MENTAL DE SEGURIDAD Falta de capacidad de las \\ autoridades PROTOCOLOS DE SEGURIDAD \\ Restricción para Evitar cumplimiento de medidas
la población vulnerable aglomeraciones Afluencia
Falta de responsabilidad social controlada Protección de la población vulnerable IMPLEMENTAR Y/O AUMENTAR OS DE SEGURIDAD Responsabilidad en el}

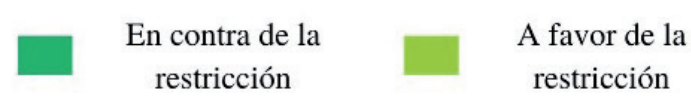

Fuente: Elaboración propia con datos de la encuesta realizada en septiembre 2020.

\footnotetext{
${ }^{21}$ Ordenanza 609-MDJM, Artículo 3 <https://bit.ly/3se6soD>
} 
Con el paso de los meses y el cambio de estación a verano, generó una gran preocupación a las autoridades locales de los distritos que conforman la Costa Verde ${ }^{22}$ por la frecuencia de usuarios en las playas y que indirectamente hacen uso de otros espacios recreativos. Es así como la PCM estableció restricciones en el uso de las playas $^{23}$, desde el veintidós de diciembre de 2020 hasta el cuatro de enero de 2021 a fin de mitigar la aglomeración de personas que visitaban estos lugares por fiestas de fin de año.

La última medida hasta febrero de 2021, la dió el Ministerio de Vivienda, Construcción y Saneamiento (2021) con la elaboración de una «Guía de acondicionamiento de espacios públicos abiertos en el marco del Estado de Emergencia Nacional por las graves circunstancias que afectan la vida de la Nación a consecuencia de la COVID-19" dando lineamientos a las municipalidades locales ante la delimitación, el acondicionamiento y cumplimiento de los protocolos sanitarios vigentes. Es así, que en los parques y losas deportivas se propone implementar elementos de seguridad vial como: conos, cintas, entre otros para demarcar las nuevas zonas de expansión; colocar paneles informativos, delimitar una trama modular para organizar los flujos y las distancias entre personas, instalación de lavatorios de manos, dispensadores de alcohol y el cumplimiento de los protocolos de seguridad bajo la desinfección y mantenimiento de estos espacios.

Ha sido evidente la falta de prospectiva ${ }^{24}$ ante el manejo de situaciones de emergencia como lo es una pandemia, la cual se redujo a medidas de restricción a fin de disminuir la vulnerabilidad de las personas ante el virus, pero que a su vez se presentaron otros problemas como la salud mental. Todas las medidas ejecutadas buenas o malas sirven como data histórica para una mejor toma de decisiones en el futuro.

\section{Conclusiones}

Se ha comprobado que la cantidad y calidad de equipamientos influye en el uso y frecuencia que las personas realizan en los espacios públicos, de manera que más de la mitad de la población encuestada prefiere trasladarse a otro ERP a fin de satisfacer sus necesidades de recreación, muchas veces sin tomar en cuenta las medidas restrictivas de desplazamiento impuestas por el gobierno.

La distribución desigual del equipamiento de los espacios públicos se encuentra relacionado a factores socioeconómicos y al tema de centralidad, el cual vulnera a los distritos que se encuentren en la periferia y produce nuevos problemas como

\footnotetext{
${ }^{22}$ Distritos que se encuentran en la Costa Verde: Callao, La Punta, La Perla, San Miguel, Miraflores, Chorrillos, San Isidro, Barranco, Magdalena del Mar y Chorrillos.

${ }^{23}$ Decreto Supremo N²02-2020-PCM <https://bit.ly/2NlpyKS>

${ }^{24}$ Es el conjunto de estudios que se realiza dentro de la planificación pensando en el futuro.
} 
los relacionados a la percepción de seguridad percibida dentro de estos espacios. Por ello, frente estas disparidades, las autoridades locales deben priorizar estos problemas a través de medidas que permitan un correcto mantenimiento de los espacios públicos y la creación de nuevos equipamientos que cumplan las necesidades de los diferentes usuarios.

La población joven es la que hace más uso de los espacios públicos, siendo los parques y losas deportivas los principales centros a los que acuden por medio de caminatas o trasladándose en transporte público; reflejando así la necesidad de desplazamiento en búsqueda de un espacio público de calidad. Además existe un incremento en el uso de las bicicletas pues es un medio de transporte seguro frente al contexto en el que vivimos, sin embargo se fomentaría a recorrer distancias más largas para acudir a nuevos espacios recreativos.

La pandemia ha visibilizado los problemas existentes en el sistema de salud pública, lo cual conlleva al despliegue de medidas para frenar la propagación del virus. Esto supuso priorizar la seguridad de las personas y la suspensión inmediata de actividades que implican contacto directo con otras; sin embargo, no se consideró que podría repercutir de manera negativa en la salud física y mental de las personas siendo la recreación una necesidad indispensable; razón por la cual, se implementaron medidas a favor de la recreación pero de uso individual en ciertos sectores, de modo que, intensifica la idea de desigualdad porque las medidas solo favorecen en su mayoría a la centralidad limeńa y limita el derecho a la recreación equitativa, igualitaria y goce de los espacios públicos para todos. Asimismo, se comprobó que las normativas dispuestas por el gobierno no son cumplidas por la población producto de la falta de monitoreo de las autoridades locales en espacios recreativos que ayuden a cumplir las restricciones, al igual de la escasa implementación de protocolos de seguridad sanitaria.

Se concluye que es necesario proporcionar espacios de calidad que aseguren el uso seguro y equitativo de los ERP, para satisfacer las necesidades sociales e individuales y evitar el desplazamiento en búsqueda de espacios idóneos, a fin de reducir el incremento de contagios; así como fomentar la responsabilidad social mediante una correcta difusión de información y la participación ciudadana.

Los estudios académicos, leyes y normativas e información geoespacial referente a los espacios públicos en el Perú aún es escasa, lo que limita un mejor análisis del territorio pero que incentiva a seguir investigando a fin de conocer las nueva dinámicas territoriales pero que incentiva a seguir investigando a fin de conocer los nuevos procesos y se concrete en propuestas de solución en beneficio de la población. 


\section{REFERENCIAS}

Boils, G. \& Galeana, S. (2017). Espacio público y vivienda: una mirada crítica a los conjuntos habitacionales. Recuperado de https://www.redalyc.org/jatsRepo/4195/419553524003/ $\mathrm{html} /$ index.html

Calero, C., Delgado, C., Ortiz, A. \& Armas, A. (2014). Espacio público y género en áreas centrales renovadas: El Raval (Barcelona) y Cuatro Torres (Santa Cruz de Tenerife). Actas del XX Coloquio de Historia Canario Americana. https://doi.org/10.13140/2.1.4945.9204

Castro, J., Patińo, F., Cardona, B. \& Ochoa, B. (2008). Aspectos asociados a la actividad física en el tiempo libre en la población adulta de un municipio Antioqueño. Revista de Salud Pública, 10(5), 679-690. https://doi.org/10.1590/S0124-00642008000500001

Cardona, B. (2008). Espacios de ciudad y estilos de vida, el espacio público y sus apropiaciones. Recuperado de: https://dialnet.unirioja.es/descarga/articulo/3157873.pdf.

D.S 008-2020-SA. Decreto supremo que declara en Emergencia Sanitaria a nivel nacional, por el plazo de noventa (90) días calendario y dicta medidas prevención y control del COVID-19. Diario Oficial El Peruano (2020). https://www.gob.pe/institucion/ minsa/normas-legales/483010-008-2020-sa

D.S. 044-2020-PCM. Decreto Supremo que declara Estado de Emergencia Nacional por las graves circunstancias que afectan la vida de la Nación a consecuencia del brote del COVID-19. Diario Oficial El Peruano (2020). https://busquedas.elperuano.pe/ normaslegales/decreto-supremo-que-declara-estado-de-emergencia-nacional-podecreto-supremo-n-044-2020-pcm-1864948-2/

Garay, K. (10 de agosto de 2020). COVID-19: Siete de cada diez peruanos ven afectados su salud mental. Diario Oficial El Peruano. https://elperuano.pe/noticia/100931covid-19-siete-de-cada-diez-peruanos-ven-afectados-su-salud-mental

García, H. \& Lara, F. (2016). Equidad en la provisión de espacios públicos abiertos: accesibilidad, percepción y uso entre mujeres de Hermosillo, Sonora. Sociedad y Ambiente, 4(10), 28-56. https://doi.org/10.31840/sya.v0i10.1651

García-Hernández, J. (2017). El espacio público en periferias desfavorecidas: Añaza y Santa Clara paradigmas de vulnerabilidad socioespacial en Santa Cruz de Tenerife. Scripta Nova. Revista Electrónica de Geografía y Ciencias Sociales, 21. https://doi.org/10.1344/ sn2017.21.19719

Gutiérrez, A. (2012). Movilidad y territorio. Herramientas para la integración Sectorial del ordenamiento a escala barrial. II Seminario Internacional Procesos Urbanos Informales. Universidad Nacional de Colombia - Sede Bogotá

Huarcaya-Victoria J. (2020). Consideraciones sobre la salud mental en la pandemia de COVID-19. Revista Peruana de Medicina Experimentaly Salud Pública, 37(2), 327-34. https://doi.org/10.17843/rpmesp.2020.372.5419 
INEI (2014). Una mirada a Lima Metropolitana. Recuperado de https://www.inei.gob.pe/ media/MenuRecursivo/publicaciones_digitales/Est/Lib1168/libro.pdf

INEI (2017). XII Censo Nacional de Población, VII de Vivienda y III de Comunidades Indígenas. Recuperado de https://censos2017.inei.gob.pe/redatam/

INEI (2020). Planos estratificados de Lima Metropolitana a nivel de manzanas según ingresos per cápita del hogar. Recuperado de https://www.inei.gob.pe/media/MenuRecursivo/ publicaciones_digitales/Est/Lib1744/libro.pdf

León, S. F. (1998). Conceptos sobre espacio público, gestión de proyectos y lógica social: reflexiones sobre la experiencia chilena. Revista Eure, XXIV(71), 27-36.

Lima Cómo Vamos (2019). Lima y Callao según sus ciudadanos. Décimo Informe Urbano de Percepción sobre Calidad de Vida en la Ciudad. Recuperado de https://www. limacomovamos.org/wp-content/uploads/2019/11/Encuesta-2019_.pdf

Lima Cómo Vamos (1 de febrero de 2021). Una cuarentena con uso de la calle. Recuperado de https://bit.ly/3aFKkO5

Lindón, A. (2006). Geografias de la vida cotidiana. Tratado de geografia humana. México: UAM Iztapalapa.

Mesclier, É. (21 de abril de 2020). Unas pistas desde la geografía para comprender mejor la epidemia de coronavirus y controlarla. Instituto Francés de Estudios Andinos. Recuperado de https://ifea.hypotheses.org/tag/evelyne-mesclier

Ministerio de Salud (2020). Guia técnica para el cuidado de la salud mental de la población afectada, familias y comunidad, en el contexto del COVID-19. Recuperado de https:// bit.ly/2ManODp

Ministerio de Vivienda, Construcción y Saneamiento (2021). Guía de acondicionamiento de espacios públicos abiertos en el marco del Estado de Emergencia Nacional por las graves circunstancias que afectan la vida de la Nación a consecuencia de la COVID-19. Recuperado de https://www.gob.pe/institucion/vivienda/informes-publicaciones/1679197guia-de-acondicionamiento-de-espacios-publicos-abiertos-en-el-marco-del-estadode-emergencia-nacional

Municipalidad de Lima (18 de junio de 2020). Municipalidad de Lima presentó resultados de estudio sobre el uso de la bicicleta en la ciudad. Noticias. Recuperado de https://www. munlima.gob.pe/noticias/item/40205-municipalidad-de-lima-presento-resultados-deestudio-sobre-el-uso-de-la-bicicleta-en-la-ciudad/

Ocampo, D. (2008). Los espacios urbanos recreativos como herramienta de productividad. Revista Escuela de Administración de Negocios, 63. https://doi.org/10.21158/01208160. n63.2008.446

Organización Mundial de la Salud (11 de marzo de 2020). Alocución de apertura del director general de la OMS en la rueda de prensa sobre la COVID-19. Recuperada de https://bit.ly/3aDspYk 
Paricio, R. \& Pando, M. (2020). Salud mental infanto-juvenil y pandemia de Covid-19 en Espańa: cuestiones y retos. Revista de Psiquiatria Infanto-Juvenil, 37(2), 30-44. https://doi.org/10.31766/revpsij.v37n2a4

Reygadas, L. \& Ziccardi, A. (2010). México: tendencias modernizadoras y persistencia de la desigualdad. Historia crítica de las modernizaciones en México, 7 vols. México: CIDE. FCE. Recuperado de http://www.aacademica.org/000-036/418

RPP (3 de enero de 2020). El 57\% de peruanos prefiere los parques como lugares de recreación. RPP Noticias. Recuperado de https://bit.ly/3dymxkU

Vega Centeno, P. (2017). La desigualdad invisible: el uso cotidiano de los espacios públicos en la Lima del siglo XXI. Territorios, 36, 23-46. https://doi.org/10.12804/revistas. urosario.edu.co/territorios/a.5097

Wang, G., Zhang, Y., Zhao, J., Zhang, J. \& Jiang, F. (2020). Mitigate the effects of home confinement on children during the COVID-19 outbreak. Lancet, 395(10228), 945-947. https://doi.org/10.1016/S0140-6736(20)30547-X

Ziccardi, A. (2013). Desigualdad urbana, espacio público y participación de la ciudadanía. Rio de Janeiro, Brasil: Editorial Letra Capital. Recuperado de http://ru.iis.sociales. unam.mx/handle/IIS/5656 